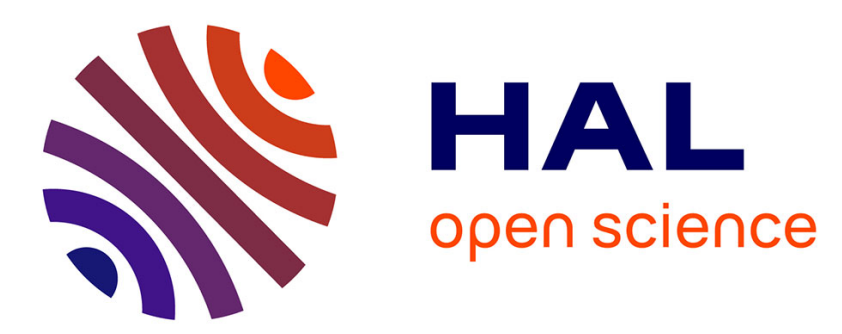

\title{
Phase Development in Sol-Gel Derived Lead Titanate: A XAS Study
}

\author{
G. Antonioli, D. Bersani, P. Lottici, I. Manzini, S. Bassi, G. Gnappi, A. \\ Montenero
}

\section{> To cite this version:}

G. Antonioli, D. Bersani, P. Lottici, I. Manzini, S. Bassi, et al.. Phase Development in Sol-Gel Derived Lead Titanate: A XAS Study. Journal de Physique IV Proceedings, 1997, 7 (C2), pp.C2-1161-C21162. 10.1051/jp4:19972173 . jpa-00255238

\section{HAL Id: jpa-00255238 https://hal.science/jpa-00255238}

Submitted on 1 Jan 1997

HAL is a multi-disciplinary open access archive for the deposit and dissemination of scientific research documents, whether they are published or not. The documents may come from teaching and research institutions in France or abroad, or from public or private research centers.
L'archive ouverte pluridisciplinaire HAL, est destinée au dépôt et à la diffusion de documents scientifiques de niveau recherche, publiés ou non, émanant des établissements d'enseignement et de recherche français ou étrangers, des laboratoires publics ou privés. 


\title{
Phase Development in Sol-Gel Derived Lead Titanate: A XAS Study
}

\author{
G. Antonioli, D. Bersani, P.P. Lottici, I. Manzini, S. Bassi, G. Gnappi* and A. Montenero* \\ Istituto Nazionale per la Fisica della Materia and Physics Department, University, Viale delle Scienze, \\ 43100 Parma, Italy \\ * Chemistry Department and CORIVE, University, Viale delle Scienze, 43100 Parma, Italy
}

\begin{abstract}
PbTiO}_{3}$ powders have been obtained by the sol-gel method using different precursors and catalysts. The whole gelation and crystallisation process was studied by means of XAS spectroscopy at the Ti K-edge and at the $\mathrm{Pb} \mathrm{L}_{\mathrm{III}}$-edge. The XANES spectra on the Ti K-edge indicate a marked change of the local environment at $500^{\circ} \mathrm{C}$. The local structure around the $\mathrm{Ti}$ atoms determined by EXAFS is similar to that observed in the pyrochlore phase for annealing temperatures below $500^{\circ} \mathrm{C}$. At this temperature both $\mathrm{Ti}$ and $\mathrm{Pb}$ environments show the occurrence of the $\mathrm{Pb}-\mathrm{O}-\mathrm{Ti}$ bonds indicating the onset of the transformation to the perovskite phase.
\end{abstract}

\section{INTRODUCTION}

Lead titanate $\mathrm{PbTiO}_{3}(\mathrm{PT})$ is a perovskite type ferroelectric material with interesting dielectric, pyroelectric and piezoelectric properties and is used for many technological applications. To obtain the expected properties, the development of a pure perovskite phase is required. The sol-gel process is well suited to produce PT powders and thin films, and is based on the preparation of a solution from organic oxides and salts, which is hydrolysed and polymerises to give metal-oxygen-metal linkages. The resulting gel is further heat treated to remove the organic residues to obtain the crystalline phases. Sol-gel derived PT powders often crystallise directly into the perovskite structure [1] but sometimes form first into the cubic paraelectric pyrochlore $\mathrm{Pb}_{2} \mathrm{Ti}_{2} \mathrm{O}_{6}$ phase [2] and subsequently transform to perovskite at higher $\left(500-700^{\circ} \mathrm{C}\right)$ temperatures.

The understanding of the interaction between lead and titanium compounds during the gel formation and the following crystallisation is of great importance to control the whole process.

\section{EXPERIMENTAL DETAILS}

Three different preparation methods, A, B and C, were used.

(A) $\mathrm{PbTiO}_{3}$ gel was obtained by mixing the solutions of lead(II) acetate trihydrate $\mathrm{Pb}\left(\mathrm{CH}_{3} \mathrm{COO}\right)_{2} 3 \mathrm{H}_{2} \mathrm{O}$ ( $\mathrm{LAT}$ ) in methoxyethanol (MOE) and of titanium isopropylalkoxide Ti $\left[\left(\mathrm{CH}_{3}\right)_{2} \mathrm{CHO}_{4}\right.$ (TPOT) in MOE.

(B) TPOT was distilled in MOE substituting the isopropyl group with the methoxyethoxy group in the titanium precursor, obtaining the tetramethoxyethoxytitanium (TMET). The distillation was performed in order to obtain more homogeneous gelation and condensation processes, because TMET has a lower reactivity than TPOT, which is hydrolysed very quickly with respect to LAT. The difference in the hydrolysis rate between LAT and TPOT may originate some precipitates or phase separation.

(C) The starting materials and the solvent were the same as in the A method, but a little amount of $\mathrm{HCl}(0.14 \%)$ as catalyst was added to the solution to favour the hydrolysis process and then the policondensation.

The obtained gels were dried in air at $125^{\circ} \mathrm{C}$ for 1 hour, then powdered and heat treated from room temperature to 700 ${ }^{\circ} \mathrm{C}$ at an heating rate of $100^{\circ} \mathrm{C} / \mathrm{h}$. For the $\mathrm{Pb}$ edge the solid samples were ground to fine powders, dispersed in boron nitride and pressed to obtain pellets suitable for transmission. At the Ti edge the absorption length of $\mathrm{PbTiO}_{3}$ is only $2 \mu \mathrm{m}$ and, to avoid thickness effects, pellets for fluorescence were obtained by pressing the pure samples. For liquids and gels an ad-hoc cell was used. The data were collected at room temperature on D32 IF CRG beamline at ESRF in Grenoble, France, using a $\mathrm{Si}(111)$ double crystal monochromator. The beam was sagittaly focused and at the Ti edge a double mirror was installed to avoid the contribution from the harmonics. EXAFS measurements were performed on A, B, C samples from the starting solutions to final $\mathrm{PbTiO}_{3}$ heat treated samples. XANES spectra were collected at the Ti edge on the B samples, starting from gels. $\mathrm{Ti}$ and $\mathrm{Pb}$ foils, $\mathrm{TiO}_{2}$ anatase, $\mathrm{Pb}_{2} \mathrm{Ti}_{2} \mathrm{O}_{6}$ pyrochlore were used as reference compounds.

The EXAFS signal was extracted from the experimental absorption coefficient using the background removal technique AUTOBK [3] whereas, for the determination of the structural parameters, the FEFFIT (UWXAFS package [4]), which uses theoretical phase functions and amplitudes from FEFF6 software [3], was used.

\section{RESULTS AND DISCUSSION}

In Fig. 1 are reported the near edge spectra at the Ti K-edge of the B samples. The XANES region shows characteristic features related to the Ti symmetry; the $1 \mathrm{~s} \rightarrow 3 \mathrm{~d}$ bound state transitions are the origin of the pre-edge peaks and are related 
to the octahedral crystal field. There is no difference between the spectra up to the $400{ }^{\circ} \mathrm{C}$ annealed samples and the cubic $\mathrm{Fd} 3 \mathrm{~m}$ pyrochlore reference, while a marked change is observed for the samples treated at higher temperatures, corresponding

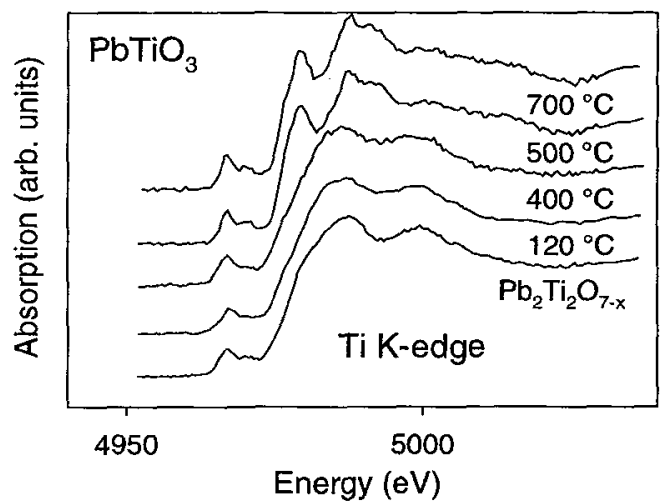

Figure 1: XANES at the Ti K-edge of the samples of B preparation.

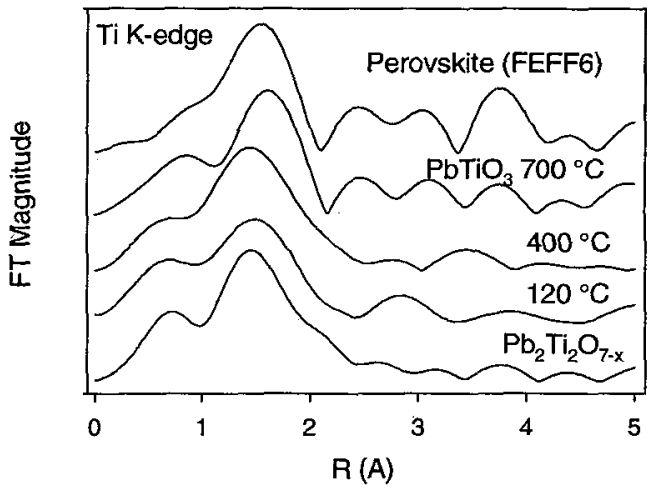

Figure 2: EXAFS Radial Distribution Function (RDF) for the samples of $B$ preparation.



Figure 3: EXAFS RDF for the samples of A preparation to the transformation into $\mathrm{P} 4 \mathrm{~mm}$ perovskite $\mathrm{PbTiO}_{3}$.

The spectra above $500{ }^{\circ} \mathrm{C}$ remain unchanged up to the higher treatment temperatures; this fact indicates that the $\mathrm{T} i$ environment undergoes a sharp transformation into a stable phase during the heating in the range $400{ }^{\circ} \mathrm{C}$ to 500 ${ }^{\circ} \mathrm{C}$.

In Fig. 2 (B samples) and in Fig. 3 (A samples) the magnitude of the Fourier transform at the $\mathrm{Ti}$ and $\mathrm{Pb}$ edges is shown, respectively. The EXAFS RDF around the $\mathrm{Ti}$ atoms shows only a peak corresponding to the first oxygen shell with six atoms at $1.94 \AA$, like in the pyrochlore reference sample, up to $400{ }^{\circ} \mathrm{C}$; this is an indication of the favoured occurrence of a pyrochlore phase instead of the more stable perovskite. A clear change in the RDF is observed for the powders treated at $\mathrm{T}>500^{\circ} \mathrm{C}$ where the main peak shifts to larger $\mathrm{R}$ value and higher coordination shells become discernible. At the Pb edge, the EXAFS RDF shows an analogous evolution for all the preparations $\mathrm{A}-\mathrm{B}-\mathrm{C}$. The first $\mathrm{Pb}-\mathrm{O}$ coordination shell dominates the spectrum up to the samples treated at $400{ }^{\circ} \mathrm{C}$, while a second $\mathrm{Pb}-\mathrm{Ti}$ peak is clearly observable for higher annealing temperatures. This suggests that the homocondensation is favoured during the gelation leading to $\mathrm{Pb}-\mathrm{O}-\mathrm{Pb}$ and $\mathrm{Ti}-\mathrm{O}-\mathrm{Ti}$ linkages instead of the heterometallic $\mathrm{Pb}-\mathrm{O}-\mathrm{Ti}$ bonds. A model of the Ti-Pb linkage through bidentate acetate bridging has been recently proposed [2]. At both $\mathrm{Ti}$ and $\mathrm{Pb}$ edges a fitting of the EXAFS data of the $700{ }^{\circ} \mathrm{C} \mathrm{A}$ and $\mathrm{C}$ samples gives results in full agreement with the crystallographic data of tetragonal $\mathrm{PbTiO}_{3}$. For the samples obtained according to the preparation $\mathrm{B}$, the EXAFS data are compatible with a perovskite phase with the coexistence of lead trititanate $\mathrm{PbTi}_{3} \mathrm{O}_{7}$ as evidenced by Raman measurements [2]. The EXAFS signals at the $\mathrm{Pb}$ edge of $\mathrm{A}$ and $\mathrm{C}$ gels are similar with that of LAT in MOE up to the annealing at $300^{\circ} \mathrm{C}$. In the B samples (distilled) the data give no evidence of the presence of the LAT precursor, even in the gel. This can be due to the more homogeneous hydrolysis process obtainable using TMET instead of TPOT, that involves the lead precursor in a larger amount.

Acknowledgments. Financial support was provided by ESRF Public User Program. We are indebted to P. Fornasini for the FEFF files used as input to FEFFIT.

\section{References}

[1] J.B. Blum, S.R. Gurkovich, J. Mater. Science 20 (1985) 4479-4482

[2] D. Bersani, P.P. Lottici, G. Gnappi, A. Montenero, S. Pigoni, J. Mater. Science 31 (1996) 3153-3157

[3] J.J. Rehr, J. Mustre de Leon, S.I. Zabinsky, R.C. Albers, J. Amer. Chem. Soc. 113 (1991) 5135-5140

[4] E.A. Stern, M. Newville, B. Ravel, Y. Yacoby, D. Haskel, Physica B 208\&209 (1995) 117-120 